\title{
Conceptualisations of Children's Life Skills Development within Holistic Approach in Southern Russia
}

\author{
Olga Shults ${ }^{1}$, and Inna Bessarabova ${ }^{2 *}$ \\ ${ }^{1}$ Linguistics Division, Volzhsky subunit of Volgograd State University (VF VolSU); Volzhsky, Russia \\ ${ }^{2}$ Education Division, Volgograd State Socio-Pedagogical University (VSSPU); Volgograd, Russia
}

\begin{abstract}
A large study within the educational project «Children`s University» and Partners' educational projects in southern Russia was aimed at investigating understandings of life skills of juniors. The analysis of the notion under research is based on the major issues of the holistic approach which is actively developed by researchers nowadays. Outcomes in the article indicate that the holistic theory becomes essential in understanding life skills and provides the basis for making conceptualisations related to the effective and positive childish development in contemporary educational settings. A new conceptual approach of children's upbringing in the framework of extra-curricular educational projects like "Children`s University" is designed and implemented in our research. The obtained results prove the idea of possible integration of holistic theories with modern educational practices, oriented to life skills development. The children involved in the project acquired new physical, mental, emotional and social life skills appreciated and used throughout their lives.
\end{abstract}

\section{Introduction}

Children's life skills are considered to be a pedagogically new phenomenon for the Russian educational theories and practical environments. Schools have practically never dealt with such pedagogical area of interest. According to the Russian State Educational Standards teachers are responsible for both literacy training and personality development of children, though in practice the school system is more achievement-oriented. The school system does not always help to recognize and support the strengths of individual pupils.

In these circumstances as a response to the mainstream education, often referred as knowledgeoriented, holistic education is becoming more and more popular.

Researchers highlight the lack of a single definition of the notion "holistic education" [1]. J. Miller describes the origin of the word holistic in the following way: "The word "holistic" comes from the Greek word "holon" and refers to a universe made up of integrated wholes that cannot simply be reduced to the sum of its parts" [2]. J. Miller in his work "The Holistic Curriculum" pointed out three basic principals of holistic education: balance, inclusion and connection. In the research he underlines the necessity of balance between individual competition and group collaboration; content of the curriculum and the information processing; knowledge and imagination; between rational and intuitive approaches to problems; quantitative and qualitative types of assessment; technique and a vision of the whole person; assessment and learning; technology and program. In other words J. Miller emphasizes that the holistic education is to maintain "the right relationship" between the part and the whole [2].

Concerning the notion of inclusiveness J. Miller states that "as long as the form of learning does not discriminate against or diminish the individual in any way it can be included" [2].

The final principle of the holistic education, like connection, includes the idea of "movement from fragmentation to connectedness". The connections between linear thinking and intuition; relationships between mind and body, relationship between domains of knowledge; relationship between self and community; relationship to the earth; relationship to the soul are given a high priority in the holistic education.

J. Hare describes the holistic education through "values that reflect this educational approach" [1]. The values have been developed from the themes that are discussed in the literature. These values 'make the collective contribution to the development of the whole student'. J. Hare elaborates the following values: relationships, integrity, desire to understand and learn, a high achiever, belief in own self-worth, compassion, loyalty.

In other words, the researchers see the holistic approach to education as a more effective alternative to the traditional knowledge-based approach for the allround development of the child throughout his life.

In recent years, the development of life skills has become more and more important within the world

* Corresponding author: lolga1177@ gmail.com 
educational community. The phenomenon of life skills is viewed from many different perspectives. The United Nation's Children's Fund (UNICEF) defines life skills as "a behavior change or behavior development approach designed to address a balance of three areas: knowledge, attitude and skills" [3]. Many researchers underline the significant role of life skills education for children: it enhances critical thinking abilities, impacts life activities, educates responsibility in the job and in future planning [4]; life skills training increases mental and physical health, pro-social behavior and decreases behavioral and social problems, as well as selfdestructive behaviors [5]; it improves interpersonal relationship and reduces aggression and behavioral problems [6]; it contributes to the extraordinary capability of teens to positive promotion and flexibility [7]; it is effective in preventing a wide range of problems such as substance abuse, teenage pregnancies, violence bullying and promotes self-confidence and self-esteem among the adolescents [8]; it improves social development, emotional and social adjustment, suggests an increase in compatibility of children and public health [9].

In other words, life skills are the abilities that help everyone face the real life by promoting physical, mental and emotional health. We suppose that in order to develop life skills, we need an effective approach to education that will help to develop the child's physical, mental, emotional and social skills, which will be necessary throughout his life. In addition, there is a need for a special academic environment in which the necessary conditions for the development of the child's life skills will be created. In our opinion, the Children's University has all the necessary characteristics for the early comprehensive development of a child in modern times.

Children's University is becoming a dynamicallydeveloping movement in Russia nowadays. The last decade has been very favourable for the development of Children's Universities in many parts of the globe. The movement of Children's Universities started in 2002 in the University of Tübingen, which pioneered this educational project and arose a spark interest among European citizens and scientists. An absolutely new format of offering children immediate insights into the world of universities and guiding to their orientation for future studies was proposed in Germany [10]. A success story of Tübingen has influenced an overwhelming progression of Children's Universities development across Western and Eastern Europe: University of Innsbruck, (2002), University of Vienna (2002), University of Bratislava (2002), University of Zürich (2004), University of Tartu (2007), University of Copenhagen (2008), Lund University (2008), University of Bucharest (2010) and others. By 2010 the number of Children's Universities had increased to 125 with the emphasis to raise motivation of children between 6 and 18 years in science and technology and to develop and administrate "science communication" [11] among them.

Theoretical approaches towards the phenomenon of Children's University are being developed at present and we fully agree with D. Overton that there has been very little research undertaken into aspects of Children's Universities [12].

As the analysis of research literature on this issue shows, there is no single model for a Children's University. The main purpose of Children's University is to introduce children to science and art at a very young age; to encourage children's curiosity; to create the conditions for developing their personal and studying skills; to teach them to search and understand new and original information instead of repeating it; to encourage and develop children's interest in science and its related disciplines.

We assume Children's University to give an opportunity for children to look in a different way at scientific and aesthetic problems, to research within their curiosity and interest, to think freely without the pressure of rules and hierarchy, to communicate with new people and to be open to new personal discoveries.

The present article focuses on the idea that Children's University provides the proper academic environment for developing, enhancing and improving children's life skills through the holistic approach to education that will help the $21^{\text {st }}$ century youngsters achieve their goals, strengthen the abilities to meet the challenges of the modern society and do well in future.

\section{Holistic approach and its effect on children's development}

The holistic education has become a familiar issue within current research education literature but there are conflicting opinions about what the holistic education is. As our research analysis shows, there is no precise definition of the holistic education. There have been claims that holistic education reflects the education of the whole child but little clarity is offered to explain what this means.

Turning to the definition of the holistic education, it is important to emphasize that it does not exist in a universal form. E. Clark describes it as a group of feelings and beliefs as well as principles and general ideas of education [13]. The researcher emphasizes that it is more than the education of the whole child and addresses the very broadest development of the whole person at the cognitive and affective levels. It covers the education of the child beyond the classroom. In other words, the holistic education encompasses the versatile child's development, encourages an individual to become the brightest one and enables him to achieve his life goals. This could be described by researchers as the idea of the holistic approach to education.

The aim of the holistic education, as the research analysis shows, is to prepare a child for the fulfilling and productive life in which his skills are constantly challenged, developed and applied as part of his lifelong learning. In other words, it is like an educational journey of constant personal discovery, which starts within the formal education and continues throughout a person's life.

R. Miller proposes that the education becomes holistic when it could be characterized by such aspects as: 
- the broad development of children and focus on their intellectual, emotional, social, physical, creative or intuitive, aesthetic and spiritual potentials;

- the open and collaborative relationships between the educator and the child at all levels within a learning community;

- the emphasis on life experience, discovery, broadening of horizons and learning beyond the classroom and the formal educational environment towards education and growth;

- the critical approach of learners to examining of the cultural, moral and political contexts of their lives. It leads learners towards actively challenging and changing cultural values to meet human needs [14].

Other researchers draw attention to the fact that holistic education offers an exciting alternative [13, 15]. Today parents and educators want more from their children's education. They are looking for an approach to education that is in tune with each child's unique needs and skills, and one that prepares the child to become a well-developed adult.

As such, the holistic education is based on the idea that children can be taught in a more natural and engaging way. Rather than different school subjects, the holistic approach seeks to empower children to use their academic learning as a foothold for their emotional and social development.

The supporters of the holistic approach have proved that it has some serious benefits. A holistic learning approach has successfully helped development of hundreds of children into successful graduates and professionals serving the society.

Education is no longer just about learning measurable skills. In the current mass educational system children have been prepared so far to memorize information and then take examinations. This approach is not only unsuccessful for children, it may even be psychologically unhealthy for some students, according to research done by R. Martin [16].

Although children should be prepared in core subjects such as mathematics, literature, or science, it is also important to teach them how to learn. The holistic education redefines not only what a core subject is, it also redefines how children should be taught.

The significant benefit of the holistic approach is not just about mental development, but it encompasses psychological, social and emotional growth of a child.

The holistic approach motivates children to learn about a subject. It instills curiosity and allows children to learn naturally and creatively. It is also attuned to each child's individual learning style, in contrast with the principles of current mass educational system.

Researches contend that the result of using the holistic approach is a child himself with developed communication and social skills, and better confidence $[17,16]$. They feel good about learning and challenging themselves with certain subjects because these things offer positive associations. Intrinsic motivation, in turn, propels them to be curious, inquisitive, and eventually be innovative adults in the workplace.

The proponents of the holistic approach maintain that holistic methodology seeks to help children develop all their skills and build their strengths [1, 2]. As such, this educational approach is inclined to inspire play-based learning, child's creativity, and his imagination. For instance, according to J. Hare, a holistic curriculum could include dance and stage performance, speech, photography, or painting (to name only a few) in addition to the "traditional" subjects [1].

More importantly, as researches confirm, the holistic approach would encourage children to make connections between subjects - for instance, using their creative skills to solve a practical scientific or social problem, or approaching a foreign language similar to the way they approach a mathematical equation [18].

It is also important that this kind of teaching does not confine only to the classroom setting. In fact, parents and educators would do well to create environments where children can experiment and explore in an enjoyable and meaningful way.

So, the holistic approach to education enables to develop a child's capacity to meet the requirements in his personal and professional life with the intention for lifelong learning and development.

We believe this could be done by developing a child's life skills in a supportive learning environment.

\section{The model of life skills}

World Health Organization (WHO) defines life skills as the abilities for adaptive and positive behavior which enable individuals to deal effectively with the demands and challenges of everyday life. Each person should have the adaptive skills like the flexibility to adjust to the life situation, positive thinking and attitude to the outer world, willingness to cope with difficulties and unpredictabilities.

As our research analysis shows, there are various opinions of what life skills mean. Different researchers underline the role of several skills which a person should possess for effective life in his social environment. For example, R. M. Lerner, C. B. Fisher, and R. A. Weinberg contend that life skills should cover the "five $C$ s"- skills: Competence in academic, social, emotional, and vocational areas; Confidence in whom one is becoming (identity); Connection to self and others; Character that comes from positive values, integrity, and strong sense of morals; Caring and compassion [19].

K.L. Pace adds "the sixth C" - Contribution to these skills [20]. He insists that by contributing to the families, neighborhoods, and communities, a child acquires practical opportunities to make use of the other five " $\mathrm{Cs}$ ".

Summarizing various opinions, we can highlight the following skills necessary for life and work of a person like: decision making; problem solving; creative thinking; critical thinking; effective communication; interpersonal relationship skills; self-awareness; empathy; coping with emotions and stress.

Evidently life skills' the nature strongly depends on the culture of the society. So, the specific characteristics of skills should be determined by the characteristics of the culture of the society. We assume the life skills to be culture-free.

After analyzing a number of approaches we have come to consider the core components of life skills as 
Friendship, Decision-making, Respect for parents and elderly.

It is necessary to define these core components. Friendship is the first core component of life skills. It symbolically covers the following life skills mentioned above: effective communication, interpersonal relationship skills, self-awareness; empathy.

To make friendship relations a child should be able to communicate effectively. Effective communication means that a person has a good command of verbal and nonverbal communication which is common in his cultural environment.

Friendship is closely related to interpersonal relationship skills which enable us to interact positively with people. This applies to establishing and maintaining good relations with people as well as with family members and friends.

Friendship is impossible without self-awareness of a person. Self-awareness means understanding the peculiarities of our human nature, the pros and cons of our character.

Self-awareness helps us to understand our emotional state as well as it serves as a basis for the formation of empathy to others. Empathy helps us tolerate people of other cultures and communicate with them.

Decision-making is the second core component of life skills. As decision-making stimulates a person to deal constructively with decisions about his life, it should symbolically cover the following life skills mentioned above: problem solving, creative thinking and critical thinking, coping with emotions and stress. Decisionmaking is connected with problem solving as the latter gives us the opportunity to cope effectively with the challenges of life.

Effective decision-making is impossible without critical thinking. Critical thinking is associated with the ability of a person to challenge external information, and evaluate it objectively.

One can't make wise decisions if he can't cope with emotions and stress. The ability to cope with emotions means an adequate assessment of one's emotions and emotions of other people as well as the impact of emotions on human actions.

Coping with stress means understanding the cause of stress, harmful effects of it on our health, and the ability to manage it.

Respect for parents and elderly is the third core component of life skills.. It should symbolically cover the following life skills mentioned above: interpersonal relationship skills, self-awareness, empathy, caring and compassion, contribution.

Interpersonal relationship skills, self-awareness and empathy have been identified above. Caring and compassion as life skills are also necessary for raising a child who respects parents and elderly.

Caring and compassion are closely connected as the researchers state [21]. Our ability to be compassionate relates to the capacity for caring required in the infantparent relationship and seems to be hard-wired into our brains. The literature suggests that only compassionate people are more effective at delivering care [9].

Compassion literally means "to suffer together." Researchers define the feeling that arises when you are confronted with another's suffering and feel motivated to relieve that suffering [22, 23]. According to R.S. Lazarus, compassion is not the same as empathy, though the concepts are related [22]. As the researcher contends, empathy refers more generally to our ability to take the perspective of and feel the emotions of another person, while compassion appears when those feelings and thoughts include the desire to help. The researchers have started to map the biological basis of compassion, suggesting its deep evolutionary purpose. Their research has shown that when we feel compassion, our heart rate slows down, we secrete the "bonding hormone" oxytocin, and regions of the brain linked to empathy, caregiving, and feelings of pleasure light up, which often results in our wanting to approach and care for other people [24].

One more approach is developed to accentuate other personal traits which is based on six essential qualities and attributes according to A. Cole-King and P. Gilbert:

1. Motivation: the motivation to be caring, supportive and helpful.

2. Sensitivity: a capacity for sensitivity and open attention, noticing when others need help.

3. Sympathy: the emotional ability to be moved by distress in others.

4. Distress tolerance: the ability to tolerate difficult emotions and situations both in ourselves and others.

5 Empathy: our ability to understand and emotionally recognise the feelings, motivations and intentions of another human being.

6 Non-judgement: compassion involves being nonjudgemental and non-condemning [21].

To sum it up, a child should have the encouragement to combine the knowledge and skills and find an outlet for contribution to one's family and community. K. Pace explains, "learning and living ethical values through moral action, service to others, and meaningful contributions are critically important to healthy character development" [20]. As parents, it is important to give support and as much freedom as necessary to allow children to exercise their character and life skills.

\section{Life skills in Children's University": research findings}

The aim of our practical research was to generate new knowledge about life skills within the educational project «Children`s University» with an intention to promote better personal outcomes for schoolchildren. An advisory group for this research was formed upon the inclusion of children from the Partners' educational projects.

The research comprised a mixed methods approach and was held in three successive phases:

1) Structured interview with Principals, teachers and parents $(\mathrm{N}=197)$;

2) A class-survey with juniors who study in our project $(\mathrm{N}=357)$; and with Partners' focus-groups representatives (64);

3) An analysis and summary of the empirical findings with the further emphasis to work out the conceptual ideas of the given research. 
The representatives of different-age-range of the Children`s University were chosen to participate on the basis of their good will and interest. The Principals, teachers and parents were also willing to make a commitment to the research and had a strong existing engagement to compare the declared ideas of modern school upbringing with the true-to-life educational practical settings organized within the project «Children`s University».

Our focus at this stage of the research is to give a thorough analysis of the empirical data obtained on Phases 1 and 2 which will contribute to the realization of Phase 3.

\subsection{Methods used in Phase 1}

As researchers we requested interviews with Principals, teachers of different subjects and parents in six schools. The total number of participants was 197 (6 Principals, 91 teachers and 100 parents), being in search of their prospective views on life skills and on the best practices of implementing new educational ideas in a school environment. Participants were invited to respond to the questions in four areas:

- what life skills mean for them;

- what life skills their juniors possess;

- which life skills are necessary to be developed;

- what «a person with no life skills» means/denotes.

Structured interviews were audio-recorded and transcribed, alongside combined with additional written notes made by Principals, teachers and parents. A specially-organized Statistics group was assigned to make the quantative and qualitative data analysis, also having obtained the consent of all the research participants to be in charge of such a job.

\subsection{Exploration of conceptual ideas used by Principals, teachers and parents}

In this part of practical research, the first objective was to study the understanding of the concept «life skills». This question meant to make the point of relating this term to the holistic approach clear.

\subsubsection{Principals $(P)$, teachers $(T)$ and parents $(P t)$ understanding of life skills}

This group of participants in our research displayed a positive attitude towards the questions under the investigation. The sayings were the following: «Life skills include team-working, caring about one`s health...» (P3); «flexibility, decision-making, selfrespect...» (T17); «empathy, friendship skills, awareness of social rules...» (Pt24); "giving help and support to each other, respecting parents and old people, being joyful most of the time» (T41).

As the analysis shows the adult-group regards life skills close to the socialization skills, friendship, respect.

The second question dealt with the understanding what life skills their juniors have and it aroused a particular interest because they witness such life skills in their juniors daily.

The responses ranged in the following way: «passion for friendship» (Pt15), «a team-working skill» (T36), «care of health» (P3), «respect for parents and elderly» (T44), «navigation skills» (Pt2).

The third question was devoted to the point of development of life skills necessary for the juniors. Such replies were given:

«the skill of stating one`s thoughts and making decisions» (T18), «the friendship skill»(Pt19), «giving support and help» (P3), «respect for people» (T31).

The fourth question aroused a lot of interest among the participants. «A person with no Life Skills» was associated with:

«poor survival» (Pt18), «unable to take care of friends» (T11), «a person who can not make decisions» (P5), «having no respect for elderly and other people» (T84), «irresponsible and having little practical experience» $(\mathrm{Pt} 21)$.

The most frequent replies have been summarized alongside with this Phase.

\subsection{Methods used in Phase 2}

The interview and focus groups were conducted throughout the children who have already been involved in our project for the last three years $(2015,2016,2017)$. Focus groups $(\mathrm{N}=64)$ were organized according to the good-will selection from the Partners' educational project in the Volgograd region. Once the participants in the research gave their preliminary consent, letters of invitation outlining the research intended aims, objectives, methods and ethical considerations, together with appropriate forms, were prepared for Principals, school teachers and parents of the children who had been selected for the project research.

The researchers prepared a questionnaire for juniors involved in our Project "Children's University» and the proposed questions were answered with a lot of enthusiasm .

We have invited 357 juniors to think and give their replies to the same questions as Principals, teachers and parents had been asked earlier. Focus project methods included also dialogues with juniors, drawing and written texts to elicit rich data of the empirical views of project participants on life skills and their intentions to develop them.

Concerning the first question about the meaning of life skills the children (C) were giving such answers: «care of health» (C104), «friendship skills» (C17), «selfrespect and respect of others» (C213), «team-building skills» (C6), «empathy and good relations with others» (C82), «working at a computer» (C15).

While responding to the second question about Life skills juniors possess themselves they emphasized: «communication skills» (C71), «making friends» (C7,1,19,43,52,102), «empathy and support» (C118), «respect for other people, especially elderly» (C 16,41,54,128,164,181,2.8,310,326,342), «decisionmaking skills») (C 28,34,66,74,99,103,164,205,289,301,314,322,348,357).

The third question dealt with the way, the children were willing to develop the following life skills in their personalities, like: «skills to cope with hardships» (C 14,28,313), «self-respect and respect of parents» 
(C42,51,64,92,115,127,164,205,218,263,294,314,333), «fast thinking》 (C16), «making friends' skills» (C5,17,62,71,94,105,128,135,146,215,338), «language skills» $(\mathrm{C} 63,94,108,157)$, «solving tasks and making decisions»

(C4,13,25,31,72,81,95,128,144,158,193,214,247,300,30

$3,341)$ «empathy and helping people» (C18,24,31,162,205).

The question «A person with no life skills » was met unanimously negative as $97 \%$ of the children assured us that they had never met such people.

\subsection{Outcomes in Phase 3}

Our practical part of the research has proved that there are similarities in the replies of adults (Principals, teachers and parents) and the children (7-11 years) from our educational project «Children's University» and Partners` educational projects (total-357 people) regarding understandings of the term «life skills». A range of answers has shown that the most frequently used the sub-skills or characteristics of life skills are:

-friendship skills

-decision-making skills

-respect for parents and olders.

Now we pass over to examine links and correlations between life skills and the holistic education that emerged inter-related due to our research analysis.

\section{Holistic education and life skills}

The purpose of this article is to bring some clarity to what contribution can be made by the holistic education to a child's life skills' development and to outline their interconnection.

The lack of clarity is an obstacle for teachers, parents and students to understand the obscure advantages that the holistic education offers. Furthermore, such clarity would facilitate a comparison with other educational initiatives and allow curriculum designers to test their claims about whether they are delivering a program of the holistic education or not.

As we have studied the contents of the core components of life skills (friendship, decision-making, respect for parents and elderly), it's important to define the core components of the holistic education. As we have summarized the chief ideas of previously analyzed research approaches on the holistic education such components like relationships, responsibility and reverence might be singled out. These life skills of a child (which cover the core components of the life skills) are better developed by the holistic approach to education as there is an evident connection between the core components of life skills and those of the holistic education. Even a brief comparison of these characteristics will reveal common features.

Relationships is the first core component of the holistic education. It is symbolically connected with Friendship - the first core component of life skills. We may say that Relationships and Friendship can surelu cover the following life skills mentioned above: effective communication, interpersonal relationship skills, selfawareness; empathy. According to the holistic approach to education, all the above-mentioned life skills can be developed and maintained through the first core component of the holistic education - Relationships.

In other words, relationships are the base for developing and maintaining the skills of a child, which make up the first core component of life skills. We may find the proof of it in the statements of different researches - the supporters of the holistic approach.

So, as C. Flake confirms, holistically educated children develop and maintain relationships through their interpersonal skills. The author underlines that they act with care, consideration, compassion and empathy in their interactions with others from a variety of backgrounds. They learn from their interactions with others. Through active listening and open-mindedness, they are ready to consider and accommodate views and opinions that challenge their own thinking [25].

Another researcher, J.P. Miller, asserts that holistically educated children demonstrate effective written and oral communication skills. Besides, they use the most appropriate way of delivering information in a variety of contexts and situations and appreciate the expectations and needs of the audience. They have sufficient confidence to change and adapt their style of communications to the situation or circumstances change [2].

R. Martin confirms that holistically educated children demonstrate good involvement behaviors. The author explains that they contribute actively and collaboratively to support group discussions and meetings. They challenge others with respect and support and develop the ideas of others to encourage the decision-making process. From their interaction with others, their experiences and learning, they take a considered global perspective on international concerns and bring an informed appreciation of the issues relevant to these concerns [16].

It's important to mention the relations between a teacher and a child within this core component of holism. As the results of the analysis of various studies show [13, 26, 17], the holistic education challenges teachers to think differently about student cognitive and affective development and to examine critically how they practise their knowledge and skills. The working relationship between a student and a teacher changes; it becomes more inclusive, dynamic and egalitarian. The teacher's skills of facilitation, guidance and mentoring will feature strongly in promoting learning and understanding at both academic and social levels. The aim for students is to understand, for example, the importance of relationships, the different ways of regarding knowledge and its evaluation, the importance of life skills in people's interaction.

Responsibility is the second core component of the holistic education. It interconnects with Decision-making - the second core component of life skills. We may say that Responsibility and Decision-making can evidently cover the following life skills mentioned above: problem solving, creative and critical thinking, coping with emotions and stress. According to the holistic approach to education, all the above-mentioned life skills can be developed and maintained through the second core component of the holistic education - Responsibility. 
In other words, Responsibility is the base for developing and maintaining the skills of a child, which make up the second core component of life skills. Different researches - the supporters of the holistic approach - prove it.

As J. Hare alleges, holistically educated children act with social and academic maturity and integrity [1]. They are confident and at ease with individuals and groups with which they may be unfamiliar and show respect for the culture, opinions and values of others. They challenge accepted wisdom maturely and develop their own understanding from this experience. They learn from their errors, take responsibility for their actions and acknowledge the input and contributions of others.

R. Martin underlines that holistically educated children take responsibility for their own personal and academic growth and the outcomes of this. They can set clear and realistic targets, prioritize conflicting demands and plan for success. They persist in their tasks and maintain high standards in their outcomes [16].

According to B. Grimes, holistically educated children demonstrate flexibility and a creative approach to problem solving [18]. In other words, they can think creatively using approaches from a number of disciplines and experiences. They feel empowered and confident to find solutions and will take risks in new and unfamiliar areas of thinking and action.

Reverence is the third core component of the holistic education. It correlates with Respect for parents and elderly - the third core component of life skills. We may say that Reverence and Respect for parents and elderly can symbolically cover the following life skills mentioned above: interpersonal relationship skills, selfawareness, empathy, caring and compassion, contribution. According to the holistic approach to education, all the above mentioned life skills can be developed and maintained through the third core component of the holistic education - Reverence. In other words, Reverence is the base for developing and maintaining the skills of a child which make up the third core component of life skills.

We have noticed that in modern conditions of dehumanization of relations in a society, the growth of juvenile delinquency and child cruelty, family crisis and the loss of moral guidelines there is a need to find opportunities for the development of ethical culture of an individual. In this respect bringing up reverence in a child towards other people and himself gets crucial importance. The analysis of different holistic studies helps to identify chief ideas on this issue:

- integration of pedagogical influences of family and school aimed at understanding parents as the highest value for a child [20];

- the relationship of parents to each other, to themselves, to children; the relationship of children to others depend on the wisdom of parental love [21];

- building reverence in a child towards parents and elderly one should respect the principles of the demanding love to a child; educational equity; eliminating physical punishment; justice for the promotion of children; education of the reasonable needs in a child [13].
C. Flake adds to these principles of education the following issues: the parents' reasonable requirements; the prevention of childhood insults; the prohibition of physical force, fear and threats in the upbringing of the child; reasonable promotion of the child; awareness of children's feelings of duty to parents [25].

Researchers have proved that the education of reverence must be carried out in the early stages of personal development of a child. Since the most important people at the initial stages of personal development parents have been, they determine aspects of the child's attitude to the world and to himself. Consequently, raising a child's reverence for his or her own parents is a prerequisite for the children to show this moral quality in relation to other people.

Reverence for parents is understood in this article as an important property of a humane personality, which manifests itself in relation to parents as a value and means the desire to understand them, empathize and to show all possible care for them.

\section{Conclusion}

In conclusion it is important to emphasize the significance of early development of children's life skills. Every person needs life skills for developing selfconfidence and emotional intelligence, as well as enhancing critical thinking, and problem solving skills; for improving communication skills; for making relationships better and handling interpersonal problems; for improving decision making ability and making informed decisions; for meeting with the challenges of everyday life; for becoming a well adjusted individual; for adapting to situations and people; for having a positive approach and not getting depressed with problems; for reducing vulnerability and high risk behavior.

Life skills bring a person greater acceptance, better relationships and a healthy, positive life. Life skills enable a person to translate knowledge (what one knows), attitudes and values (what one believes and feels) into actual abilities and actions (what one does and how he does it).

In our opinion the holistic education is the most effective educational approach for developing a child's life skills. The holistic education calls for children to take ownership of their own development. This ownership will take different forms at different ages and levels of a child's maturity. Nevertheless, it is a key element within the holistic education and teachers will need to be at the forefront of driving this issue and encouraging this ownership.

Learning is a lifelong experience. A major difference between the holistic approach and the traditional knowledge-based approach is that the former adopts a planned and considered approach to the development beyond academic considerations and at the very broadest level. The holistic education delivers personal and interpersonal skills that will bring considerable advantages to the children's progress beyond their formal education.

The holistic education expands and intensifies the process of education. It represents a planned approach 
that encourages personal responsibility, promotes a positive attitude to learning and develops social skills. These are essentials in the modern world in which we live, especially Relationships, Responsibility and Reverence which adequately correlate with such life skills as Friendship, Decision-making and Respect for parents and elderly.

As our research has proved that Children's University has a great educational potential in terms of the development of children's life skills through a holistic approach to learning. The educational journey starts the process of self-actualization and self-realization of a child through relationships with other individuals, groups and the academic world around them.

The goals and objectives of the Children's University correspond to the educational opportunities of the child of any identity without discrimination against their nation, gender, age, parents' financial status. The goals include: 1) ensuring access for all children without restrictions and on a voluntary basis; 2) creating the atmosphere of respect; 3) promoting the role of universities in organizational, didactic and research aspects. Among the objectives of the Children's University are noted 1) to encourage children's curiosity and their ability to think critically, which is the main driver of science and research; 2) to familiarize children with the idea of universities; its representation in the academic culture to understand the role of universities in society as a whole; 3 ) organization of work with children in such a way as to improve the status of universities and make them more accessible and effective; 4) holding meetings between children and universities (as a community of teaching staff and students); 5) increasing the interest of children in various fields of science (from Humanities to Social Sciences and Natural Sciences) in a variety of scientific methods, without commercial benefits; 6) informing young people about future education and career.

During the activities within the Project "Children's University" the development of the children's life skills through the holistic education was given a special emphasis: Analyzing the current state and perspectives of Children's University world dissemination, we have come to the conclusion that such projects can not be considered as a temporary phenomenon or an advertising University method but as an independent basis for life skills development in the holistic dimension. Existing formal education is merely the starting point for this lifelong educational process.

\section{References}

1. J. Hare, J. Res. Int. E. 5(3), 23-25 (2006)

2. J. P. Miller, The Holistic Curriculum (OISE Press, 2007)

3. R. Pillai, The Course of a Life-skills Program (http://www.ingentaconnect.com, 2011)

4. Z. Roodbari, E. Sahdipoor, S. Ghale, Indian J. Fund. and Appl. Life Sciences 3(3), 382-390 (2013)

5. M. Ramesht, C. Farshad, The Role of Life Skills and Training in Prevention of Drug Abuse in Students (Iran Uni. Science and Tech., 2016)
6. T. Yankey, U.N Biswas, J. Refugee Studies 25(4), 326-337 (2012)

7. J. Tuttle, N. Campbell-Heider, T. David, J. Pediat. Health C. 20(3), 184-191 (2016)

8. J. Puspakumara, Effectiveness of Life-skills Training Program (Rajarata Uni. Sri Lanka, 2011)

9. P. Yadav, N. Iqbal, J. Indian Acad. Appl. Psy. 35, 61-70 (2009)

10. P. Frankenberg, EUCU.NET White Book, Vienna 5 (2008)

11. J. K. Gilbert, S. M. Stocklmayer, Communication and Engagement with Science and Technology (Routledge, 2013)

12. T. D. Overton, Procedia Soc. Beh. Sciences 2 (2010)

13. E. T. Clark, A Search for Wholeness in Education (Hol. Ed. Press, 2014)

14. R. Miller, New Directions in Education: Selections from Holistic Education Review. (Hol. Ed. Press, 1991)

15. R. Nava, An Alternative Approach to Education (Hol. Ed. Press, 2011)

16. R. Martin, Holistic Education Research. (Am. Ed. Res. Ass., 2014)

17. S. Forbes, The Idea of Holistic Education. (Found. Ed. Renewal, 2013)

18. B. Grimes, A Comprehensive Research of Holistic Education (Found. Ed. Renewal, 2015)

19. R. M. Lerner, C. B. Fisher, R. A. Weinberg, Child Dev. 71 (1), 11-20 (2000)

20. K.L. Pace, The Character of Moral Communities (Sage Pub. Inc., 2003)

A. Cole-King, P.Gilbert, J. Hol. Health C. 8(3), 29-37, (2011)

21. R. S. Lazarus, Emotion and Adaptation. (OUP, 1991)

22. M. C. Nussbaum, Soc. Philos. Policy 13, 27-58, (1996)

23. J. L. Goetz, D. Keltner, E. Simon-Thomas, Psy. Bulletin Am. Psy. Ass. 136 (3), 351-374 (2010)

24. C. Flake, The Principles of Holistic Approach (Hol. Ed. Press, 2016)

25. S. Conti, The Perspectives of Holistic Education (Westview Press, 2013) 